\title{
IncRNA H19 promotes viability and epithelial-mesenchymal transition of lung adenocarcinoma cells by targeting miR-29b-3p and modifying STAT3
}

\author{
LIHUA LIU, LINLIN LIU and SIJING LU
}

Department of Respiration, The First Affiliated Hospital of Jinzhou Medical University, Jinzhou, Liaoning 121000, P.R. China

Received April 19, 2018; Accepted September 24, 2018

DOI: $10.3892 /$ ijo.2019.4695

\begin{abstract}
Considering the joint contribution of long non-coding RNAs (lncRNAs) and microRNAs (miRNAs/miRs) to tumorigenesis, the aim of the present study was to investigate whether and how lncRNA H19 targets miR-29b-3p to affect the progression of lung adenocarcinoma by the modulation of signal transducer and activator of transcription 3 (STAT3). A total of 305 lung adenocarcinoma tissues and four human lung adenocarcinoma cell lines (i.e. Calu-3, NCI-H1975, A549 and NCI-H23) were used. pcDNA3.1-H19, short interfering RNA (si-)H19, miR-29b-3p mimic, miR-29b-3p inhibitor and negative control (NC) were transfected into the cells, and the proliferation, viability and apoptosis of the cells were determined using a Cell Counting Kit-8 assay, colony formation assay and flow cytometry, respectively. The results indicated that highly expressed H19 and poorly expressed miR-29b-3p could serve as predictors for the poor prognosis of lung adenocarcinoma patients. Additionally, si-H19 and miR-29b-3p mimic significantly increased the apoptosis of lung adenocarcinoma cells, and decreased the survival rate and viability of cells. Simultaneously, expression of epithelial-mesenchymal transition (EMT)-specific proteins was significantly altered, i.e. increased epithelial cadherin expression, as well as decreased vimentin, Snail and Slug expression. Furthermore, miR-29b-3p was verified to be targeted and regulated by H19, and STAT3 was targeted and modified by miR-29b-3p. Ultimately, STAT3 was identified to decrease lung adenocarcinoma cell viability, survival, apoptosis and EMT imposed by miR-29b-3p. In conclusion, the results of the present study indicated that IncRNA H19/miR-29b-3p/STAT3 signaling was involved in the development of lung adenocarcinoma, which may be critical for developing effective diagnostic and treatment strategies for lung adenocarcinoma.
\end{abstract}

Correspondence to: Dr Sijing Lu, Department of Respiration, The First Affiliated Hospital of Jinzhou Medical University, 2 The Fifth Section of Renmin Street, Jinzhou, Liaoning 121000, P.R. China E-mail: Res_lusijing@126.com

Key words: lung adenocarcinoma, long non-coding RNA H19, microRNA-29b-3p, signal transducer and activator of transcription 3, signaling

\section{Introduction}

Owing todifferentiated stages and morphologicalcharacteristics, lung cancer may be classified into small cell lung cancer and non-small cell lung cancer (NSCLC) (1). NSCLC cases account for $<85 \%$ of all lung cancer cases, and are currently treated primarily by surgery and chemotherapy $(2,3)$. However, the typically late diagnosis of lung cancer has led to a relatively low 5 -year survival rate of $15 \%$, therefore identification of novel biomarkers for diagnosing early-stage lung cancer is of high importance (4). In addition, development of biomarkers also satisfies the requirements for personalized treatment, which might assist in specific diagnosis and treatment of NSCLC (5).

With the progress of human genome sequencing, it was observed that merely $2 \%$ of total RNA could be translated into proteins, and other RNAs that were not transcribed were classified as non-coding RNA (ncRNA) (6,7). ncRNAs may be divided into housekeeping ncRNAs and regulatory RNAs, and the latter are further subcategorized into small ncRNAs (<200 nt) and long non-coding RNAs (lncRNAs; $\geq 200 \mathrm{nt}$ ) (8). The reverse transcription-quantitative polymerase chain reaction (RT-qPCR) is the standard technique for detecting lncRNA expression, owing to its high sensitivity and precision (9). The aberrantly expressed lncRNAs were extrapolated to be associated with human disorders (10), since they were involved with a number of biological processes, including X-chromosome inactivation, reactivation of pluripotent stem cells, differentiation of myocytes, cell apoptosis and cell invasion (11-13). Of note, it has been identified that development of lung cancer was accompanied by varied expression of IncRNAs, and certain lncRNAs have been identified as principal biomarkers for lung cancer development (14,15). For instance, expression of lncRNA H19 was increased with increased tumor size and advanced tumor-node-metastasis (TNM) staging when NSCLC tissues were investigated (16). Additionally, H19 promoted epithelial-mesenchymal transition (EMT) and metastasis of lung cancer cells by decreasing E-cadherin expression and facilitating Slug expression $(17,18)$. These previous studies all indicate that $\mathrm{H} 19$ is involved in the etiology of lung cancer, including lung adenocarcinoma.

Inaddition,lncRNAs werehypothesized to actonmicroRNAs (miRNAs/miRs) in various ways $(19,20)$. For example, H19 was documented to sponge miR-200b/c in mediating EMT of breast cancer cells, whereas the reverse transition was triggered 
when H19 sponged let-7b (21). H19 could also directly target miR-29b-3p to boost metastasis of bladder cancer cells by downregulating DNA methyltransferase 3B expression (22). Of note, miR-29b-3p was identified to antagonize the aggravation of NSCLC (23), and signal transducer and activator of transcription 3 (STAT3), the downstream target molecule of miR-29b-3p, exhibited an increase in expression in lung cancer cells (24). However, few studies have stated clearly whether H19 could function on miR-29b-3p and STAT3 to modify the pathogenesis of lung adenocarcinoma.

Thus, the aim of the present study was to preliminarily elucidate the underlying mechanismbetweenH19/miR-29b-3p/STAT3 axis and the development of lung adenocarcinoma, which may assist in identifying potential biomarkers for diagnosing and treating lung adenocarcinoma.

\section{Materials and methods}

Chip analysis. starBase software (version 2.0; starbase. sysu.edu.cn) (25) was applied to compare H19 expression between cancer tissues and normal tissues, and to predict the downstream miRNA of H19. Using this software, the expression data of H19 and miR-29b-3p within lung adenocarcinoma tissues were drawn from The Cancer Genome Atlas project (cancergenome.nih.gov) by way of the Genomic Data Commons Data Portal (portal.gdc.cancer. gov). Furthermore, the potential target sites of H19 and miR-29b-3p were predicted using miRanda (www.miranda. org), and were investigated further on basis of consideration of Argonaut (Ago) cross-linking immunoprecipitation clusters. The Ago protein could greatly influence miRNA processing and miRNA-derived cleavage within animals $(26,27)$, thereby affecting the target sites between IncRNAs and miRNAs.

Collection of samples. A total of 305 lung adenocarcinoma tissues were collected from patients who underwent surgical excision in The First Affiliated Hospital of Jinzhou Medical University (Jinzhou, China) between March 2016 and January 2017. The lung adenocarcinoma subjects were diagnosed according to the standards of the 2015 World Health Organization classification (28), in which the definition of adenocarcinoma has been modified, and thereby the probability of NSCLCs diagnosed as adenocarcinoma was increased. The normal pulmonary tissues obtained as the control group were located $>3 \mathrm{~cm}$ from the lung adenocarcinoma tissues. The present study was approved by the ethics committee of The First Affiliated Hospital of Jinzhou Medical University and all patients provided written informed consent.

Cell culture. Human lung adenocarcinoma cell lines (Calu-3, NCI-H1975, A549 and NCI-H23) and normal lung cell line (HLF-a) were purchased from the American Type Culture Collection (Manassas, VA, USA). Cells were seeded in Dulbecco's modified Eagle's medium (HyClone; GE Healthcare, Logan, UT, USA) containing $10 \%$ fetal bovine serum, $1 \times 10^{5} \mathrm{U} / 1$ penicillin and $1 \times 10^{5} \mathrm{U} / 1$ streptomycin. The cells were cultured in $5 \% \mathrm{CO}_{2}$ and $90 \%$ humidity at $37^{\circ} \mathrm{C}$.

$R T$ - $q P C R$.Total RNA was extracted fromall cell lines and tissues using TRIzol ${ }^{\circledR}$ reagent (Invitrogen; Thermo Fisher Scientific,
Inc., Waltham, MA, USA), and its purity and concentration were determined spectrophotometrically. Extracted RNAs were reverse-transcribed into cDNAs using a Superscript II reverse transcription kit (Invitrogen; Thermo Fisher Scientific, Inc.), according to the manufacturer's protocol, with reaction conditions of: i) $42^{\circ} \mathrm{C}$ for $60 \mathrm{~min}$, ii) $95^{\circ} \mathrm{C}$ for $5 \mathrm{~min}$, and iii) $4^{\circ} \mathrm{C}$ for $10 \mathrm{~min}$. The cDNAs were subjected to PCR using a SYBR-Green master kit (Applied Biosystems; Thermo Fisher Scientific, Inc.), according to the manufacturer's protocol. The PCR conditions for H19 and GAPDH were: i) Pre-denaturation at $95^{\circ} \mathrm{C}$ for $2 \mathrm{~min}$, and ii) 40 cycles of denaturation at $95^{\circ} \mathrm{C}$ for $15 \mathrm{sec}$, annealing at $60^{\circ} \mathrm{C}$ for $30 \mathrm{sec}$ and extension at $72^{\circ} \mathrm{C}$ for $15 \mathrm{sec}$. Furthermore, the PCR conditions for miR-29b-3p and U6 were: i) Pre-denaturation at $95^{\circ} \mathrm{C}$ for $30 \mathrm{sec}$, and ii) 40 cycles of denaturation at $95^{\circ} \mathrm{C}$ for $10 \mathrm{sec}$, annealing at $60^{\circ} \mathrm{C}$ for $30 \mathrm{sec}$ and extension at $70^{\circ} \mathrm{C}$ for $5 \mathrm{sec}$. GAPDH was used as the internal reference for H19, and U6 was used as the internal reference for miR-29b-3p. The relative expression of H19 and miR-29b-3p were calculated according to the $2^{-\Delta \Delta C q}$ method (29). Primers (Table I) were designed using Primer Express software (version 2.0; Applied Biosystems; Thermo Fisher Scientific, Inc.), and were synthesized by Sangon Biotech Co., Ltd. (Shanghai, China).

Western blotting. Total protein from tissues and cells was extracted using radioimmunoprecipitation assay lysis buffer (Sigma-Aldrich; Merck KGaA, Darmstadt, Germany) that contained proteinase inhibitor (Roche Diagnostics, Indianapolis, IN, USA), and its concentration was determined using a Bicinchoninic Acid protein assay kit (Thermo Fisher Scientific, Inc.), according to the manufacturer's protocol. Subsequently, the protein extracts ( $30 \mu \mathrm{g}$ for each sample) were separated by SDS-PAGE (6 or 10\% polyacrylamide gel), and transferred onto polyvinylidene difluoride membranes. The membranes were blocked with $5 \%$ skimmed milk in Tris-buffered saline containing $0.25 \%$ Tween- 20 at room temperature for $1 \mathrm{~h}$ before overnight incubation at $4^{\circ} \mathrm{C}$ with rabbit anti-human monoclonal antibodies against STAT3 (1:1,000; cat. no. ab68153; Abcam, Cambridge, MA, USA), epithelial (E-)cadherin (1:1,000; cat. no. 20874-1-AP), vimentin (1:1,000; cat. no. 10366-1-AP), Snail (1:1,000; cat. no. 13099-1-AP) (all from ProteinTech Group, Inc., Chicago, IL, USA), Slug (1:1,000; cat. no. sc-166476; Santa Cruz Biotechnology, Inc., Dallas, TX, USA), $\beta$-actin (1:1,000; cat. no. ab8227; Abcam) and GAPDH (1:1,000; cat. no. 5174; Cell Signaling Technology, Inc., Danvers, MA, USA). Corresponding horseradish peroxidase-conjugated mouse anti-rabbit secondary antibodies (1:10,000; cat. no. 93702; Cell Signaling Technology, Inc.) were added for another $1 \mathrm{~h}$ at room temperature. Enhanced chemiluminescence detection reagent (EMD Millipore, Billerica, MA, USA) was applied for development, and the band images were analyzed utilizing a Gene Genius gel imaging system (Syngene Europe, Cambridge, UK).

Cell transfection. Short interfering RNA (siRNA) for H19 (si-H19; $50 \mathrm{nM}$ ), negative control siRNA (si-NC; $50 \mathrm{nM}$ ), H19-overexpression plasmid (pcDNA3.1-H19; $2 \mu \mathrm{g}$ ), pcDNA3.1 $(2 \mu \mathrm{g})$, miR-29b-3p mimic $(50 \mathrm{nM})$, miR-29b-3p inhibitor (50 nM), STAT3-overexpression plasmid (pcDNA3.1-STAT3; 
Table I. Primer sequences for miR-29b-3p, lncRNA H19, STAT3, U6 and GAPDH.

\begin{tabular}{ll}
\hline RNA & \multicolumn{1}{c}{ Primer sequence } \\
\hline miR-29b-3p & F: 5'-ACACTCCAGCTGGGTAGCACCATT \\
& TGAAATC-3' \\
& R: 5'-TGGTGTCGTGGAGTCG-3' \\
U6 & F: 5'-CGCCCCACCCCTCCAG-3' \\
& R: 5'-CCGCCCAGACCCTCAGACT-3' \\
lncRNA H19 & F: 5'-CTGTAACCGGCGCCAGAA-3' \\
& R: 5'-TGCATGGGAGAGCCCAGA-3' \\
GAPDH & F: 5'-TGTGGGCATCAATGGATTTGG-3' \\
& R: 5'-ACACCATGTATTCCGGGTCAAT-3'
\end{tabular}

miR, microRNA; lncRNA, long non-coding RNA; STAT3, signal transducer and activator of transcription 3; F, forward; R, reverse.

$2 \mu \mathrm{g}$ ), STAT3 siRNA (si-STAT3, $2 \mu \mathrm{g}$ ) and negative control (NC) were all designed and synthesized by Guangzhou RiboBio Co., Ltd. (Guangzhou, China). The sequences of H19-siRNA1\#, H19-siRNA2\# and H19-siRNA3\# were 5'-CCGUAAUUC ACUUAGA AGAdTdT-3', 5'-CACAUAGAAAGGCAGGA UAdTdT-3' and 5'-CCUUCUAAACGAAGGUUUAdTdT-3', respectively. The sequence of si-NC was 5'-UUCUCCGAAC GUGUCACGUTT-3'. The sequences for miR-29b-3p mimic, miR-29b-3p inhibitor and miR-NC were 5'-UAGCACCAUUU GAAAUCAGUGUU-3', 5'-AACACUGAUUUCAAAUGGUG CUA-3' and 5'-UUCUCCGAACGUGUCACGUTT-3', respectively. The forward and reverse primers for si-STAT3 were 5'-AAGCAGCAGCTGAACAACATGTTCAAGAGACATGT TGTTCAGCTGCTGCTT-3' and 5'-AAGCAGCAGCTGAAC AACATGTCTCTTGAACATGTTGTTCAGCTGCTGCTT-3', respectively. Lipofectamine ${ }^{\circledR} 2000$ (Invitrogen; Thermo Fisher Scientific, Inc.) was used for cell transfection, according to the manufacturer's protocol. After $48 \mathrm{~h}$ of transfection, Calu-3 and NCI-H1975 cell lines were used for subsequent experiments.

Colony formation assay. Calu-3 and NCI-H1975 cell lines were inoculated into 6-well plates at a density of 1,000 cells/well. Following continuous culture for 10 days, the cells were fixed with methanol for $20 \mathrm{~min}$. Finally, the cells were stained with crystal violet (Sigma-Aldrich; Merck KGaA) for 15 min, and the number of colonies that included $>50$ cells was determined using an inverted light microscope (Leica Microsystems $\mathrm{GmbH}$, Wetzlar, Germany) at x100 magnification.

Cell proliferation assay. Calu-3 and NCI-H1975 cell lines were seeded in 96-well plates at a density of 2,500 cells/well. At 24, 48, 72 and $96 \mathrm{~h}$ after inoculation, Cell Counting Kit-8 (CCK-8) solution was added to each well (Abmole Bioscience Inc., Houston, TX, USA) at $10 \mu \mathrm{l} /$ well. Following incubation at $37^{\circ} \mathrm{C}$ for $1 \mathrm{~h}$, the absorbance at $450 \mathrm{~nm}$ was determined to calculate the cell proliferation rate.

Cell apoptosis assay. Calu-3 and NCI-H1975 cell lines were resuspended in $500 \mu 1$ binding buffer, and were stained with $5 \mu$ l Annexin V-fluorescein isothiocyanate (FITC) and $10 \mu 1$ propidium iodide (PI) in the dark for $15 \mathrm{~min}$, using an Annexin V-FITC cell apoptosis kit (Beyotime Institute of Biotechnology, Haimen, China), according to the manufacturer's protocol. Subsequently, flow cytometry (model, ELITE; laser wavelength, $488 \mathrm{~nm}$; power, $15 \mathrm{~mW}$; Beckman Coulter, Inc., Brea, CA, USA) was used to analyze cell apoptosis. On the flow cytometry scattergrams, cells in the lower-left quadrant labeled as FITC-/PI' and the upper-left quadrant labeled as $\mathrm{FITC}^{-} / \mathrm{PI}^{+}$were designated as viable cells. In contrast, cells in the upper-right quadrant tagged as $\mathrm{FITC}^{+} / \mathrm{PI}^{+}$were designated as necrotic cells, and those in the lower-right quadrant labeled as $\mathrm{FITC}^{+} / \mathrm{PI}^{-}$were designated as early-apoptotic cells.

Dual-luciferase reporter gene assay. The H19 fragments that contained specific miR-29b-3p-binding sites were cloned into the pmirGLOdual-luciferaseexpressionvector(PromegaCorporation, Madison, WI, USA), through which pmirGLO-H19-Wt was formed. Furthermore, the same binding sites of miR-29b-3p in H19 were mutated to construct pmirGLO-H19-Mut. Using a similar approach, pmirGLO-STAT3-Wt that contained miR-29b-3p-binding sites and pmirGLO-STAT3-Mut vectors were constructed. Cells that had been transfected with pmirGLO-H19-Wt, pmirGLO-H19-Mut, pmirGLO-STAT3-Wt, pmirGLO-STAT3-Mut or pmirGLO vector were, respectively, transfected with miR-29b-3p mimic and miR-NC. At $\sim 48 \mathrm{~h}$ after transfection, luciferase activity was determined using the Dual-Luciferase Reporter assay system (Promega Corporation).

Statistical analysis. All statistical analyses were performed using SPSS software (version 17.0; SPSS, Inc., Chicago, IL, USA). The measurement data that conformed to normal distribution are expressed as the mean \pm standard deviation, and the enumeration data are represented as the frequency or percentage. Inter-group comparisons among the measurement data were performed using Student's t test or analysis of variance with a Bonferroni post hoc test, whereas the enumeration data were compared using a $\chi^{2}$ test. The correlations between H19 expression and miR-29b-3p expression, as well as between miR-29b-3p expression and STAT3 expression, were determined by performing Spearman's rank correlation test. Furthermore, the Kaplan-Meier method was utilized to calculate the accumulative survival rate of patients with lung adenocarcinoma, with the log-rank test adopted for univariate analysis of prognostic factors. The Cox regression model was used for the multivariate analysis, to determine the association of H19/miR-29b-3p expression with clinicopathological features and overall survival of patients with lung adenocarcinoma. $\mathrm{P}<0.05$ was considered to indicate a statistically significant difference.

\section{Results}

Comparison of $H 19$ and miR-29b-3p expression between lung adenocarcinoma tissues/cells and normal tissues/cells. The chip analysis results collected from The Cancer Genome Atlas starBase (version 2.0) data portal indicated that H19 expression in lung cancer tissues was significantly increased compared with in paracarcinoma tissues $(\mathrm{P}<0.05)$ and that 
Table II. Association between clinicopathological characteristics and lncRNA H19/miR-29b-3p expression in patients with lung adenocarcinoma.

\begin{tabular}{|c|c|c|c|c|c|c|}
\hline \multirow[b]{2}{*}{ Clinical characteristic } & \multicolumn{3}{|c|}{ lncRNA H19 expression } & \multicolumn{3}{|c|}{ miR-29b-3p expression } \\
\hline & Low & High & P-value & Low & High & P-value \\
\hline \multicolumn{7}{|l|}{ Age, years } \\
\hline$>56$ & 41 & 116 & 0.93 & 107 & 50 & 0.51 \\
\hline$\leq 56$ & 38 & 110 & & 106 & 42 & \\
\hline \multicolumn{7}{|l|}{ Sex } \\
\hline Female & 39 & 104 & 0.608 & 100 & 43 & 0.973 \\
\hline Male & 40 & 122 & & 113 & 49 & \\
\hline \multicolumn{7}{|l|}{ History of smoking } \\
\hline Yes & 45 & 84 & 0.002 & 84 & 45 & 0.124 \\
\hline No & 34 & 142 & & 129 & 47 & \\
\hline \multicolumn{7}{|l|}{ Tumor diameter, cm } \\
\hline$>1.56$ & 46 & 162 & 0.027 & 153 & 55 & 0.038 \\
\hline$\leq 1.56$ & 33 & 64 & & 60 & 37 & \\
\hline \multicolumn{7}{|l|}{ TNM staging } \\
\hline $\mathrm{I}+\mathrm{II}$ & 41 & 85 & 0.026 & 76 & 50 & 0.002 \\
\hline III+IV & 38 & 141 & & 137 & 42 & \\
\hline \multicolumn{7}{|l|}{ Invasion } \\
\hline Yes & 53 & 178 & 0.037 & 170 & 61 & 0.012 \\
\hline No & 26 & 48 & & 43 & 31 & \\
\hline \multicolumn{7}{|l|}{ Histological subtype } \\
\hline AIS & 46 & 28 & & 35 & 39 & \\
\hline MIA & 23 & 18 & & 20 & 21 & \\
\hline Lepidic predominant & 10 & 19 & & 15 & 14 & \\
\hline Acinar predominant & 28 & 22 & & 23 & 27 & \\
\hline Papillary predominant & 17 & 26 & & 23 & 20 & \\
\hline Micropapillary predominant & 12 & 11 & & 10 & 13 & \\
\hline Solid predominant with mucin production & 14 & 17 & & 13 & 18 & \\
\hline Invasive mucinous adenocarcinoma & 6 & 8 & & 7 & 7 & \\
\hline
\end{tabular}

Significant P-values are in bold. lncRNA; long non-coding RNA; miR, microRNA; TNM, tumor-node-metastasis; AIS, adenocarcinoma in situ; MIA, minimally invasive adenocarcinoma.

there was a negative correlation between $\mathrm{H} 19$ expression and miR-29b-3p (Fig. 1). It was also identified that H19 expression was significantly increased in the lung adenocarcinoma tissues collected compared with in adjacent paracancerous tissues $(\mathrm{P}<0.05)$, and $\mathrm{miR}-29 \mathrm{~b}-3 \mathrm{p}$ expression in lung adenocarcinoma was significantly decreased compared with in adjacent paracancerous tissues $(\mathrm{P}<0.05)$ (Fig. 2A). Furthermore, H19 expression in Calu-3, NCI-H1975, A549 and NCI-H23 cell lines were also increased compared with that in the HLF-a cell line $(\mathrm{P}<0.05)$; in contrast, the expression of $\mathrm{miR}-29 \mathrm{~b}-3 \mathrm{p}$ was significantly decreased in the cancer cell lines compared with in the HLF-a cell line $(\mathrm{P}<0.05)$ (Fig. 2B). Since the expressions of H19 and miR-29b-3p were altered most significantly within Calu-3 and NCI-H1975 cell lines when compared with HLF-a cell line, these cell lines were selected for the subsequent cell experiments. In addition, Spearman's rank correlation analysis identified that there was a negative correlation between miR-29b-3p expression and H19 expression among the lung adenocarcinoma tissues investigated ( $\mathrm{P}<0.05$; Fig. 2C). Clinicopathological analyses identified that increased H19 expression and decreased miR-29b-3p were associated with longer tumor diameter, more advanced TNM stage and invasive lung carcinoma ( $\mathrm{P}<0.05$; Table II, Fig. $2 \mathrm{D}$ and $\mathrm{E})$. The results of multivariate analyses also indicated that H19 expression, miR-29b-3p expression, tumor diameter and TNM staging could serve as the independent predictors for poor survival rate of patients with lung carcinoma patients (all $\mathrm{P}<0.05$; Table III).

$H 19$ and $\mathrm{miR}-29 \mathrm{~b}-3 p$ regulate proliferation, viability and apoptosis of lung adenocarcinoma cells. H19 expression in Calu-3 and NCI-H1975 cells was significantly increased following transfection with pcDNA3.1-H19 $(\mathrm{P}<0.05)$, yet it was significantly decreased following transfection with si-H19 ( $\mathrm{P}<0.05)$ (Fig. 3A). Similarly, miR-29b-3p expression was significantly increased and decreased following 
Table III. Association between clinical characteristics and overall survival of patients with lung adenocarcinoma patients.

\begin{tabular}{|c|c|c|c|c|c|c|}
\hline \multirow[b]{2}{*}{ Clinical characteristic } & \multicolumn{3}{|c|}{ Univariate analysis } & \multicolumn{3}{|c|}{ Multivariate analysis } \\
\hline & Hazard ratio & $95 \% \mathrm{CI}$ & P-value & Hazard ratio & $95 \% \mathrm{CI}$ & P-value \\
\hline \multicolumn{7}{|l|}{ IncRNA H19 expression } \\
\hline Low vs. high & 0.35 & $0.21-0.60$ & $<0.001$ & 0.45 & 0.25-0.81 & $\mathbf{0 . 0 0 7}$ \\
\hline \multicolumn{7}{|l|}{ miR-29b-3p expression } \\
\hline Low vs. high & 2.5 & $1.52-4.12$ & $<0.001$ & 1.77 & 1.03-3.07 & 0.04 \\
\hline \multicolumn{7}{|l|}{ Age, years } \\
\hline$>56$ vs. $\leq 56$ & 1.3 & $0.83-2.05$ & 0.257 & 1.25 & $0.76-2.05$ & 0.381 \\
\hline \multicolumn{7}{|l|}{ Sex } \\
\hline Female vs. male & 1 & $0.63-1.58$ & 0.998 & 0.99 & $0.60-1.63$ & 0.971 \\
\hline \multicolumn{7}{|l|}{ History of smoking } \\
\hline Yes vs. no & 0.9 & $0.57-1.43$ & 0.662 & 1.13 & $0.68-1.88$ & 0.648 \\
\hline \multicolumn{7}{|l|}{ Tumor diameter, $\mathrm{cm}$} \\
\hline$>1.56$ vs. $\leq 1.56$ & 2.58 & $1.57-4.23$ & $<0.001$ & 2.45 & 1.43-4.19 & 0.001 \\
\hline \multicolumn{7}{|l|}{ TNM staging } \\
\hline I+II vs. III+IV & 0.38 & $0.24-0.61$ & $<0.001$ & 0.43 & $0.25-0.72$ & 0.001 \\
\hline \multicolumn{7}{|l|}{ Invasion } \\
\hline Yes vs. no & 2.06 & $1.21-3.49$ & 0.008 & 1.23 & $0.68-2.22$ & 0.503 \\
\hline
\end{tabular}

Significant results are in bold. CI, confidence interval; lncRNA, long non-coding RNA; miR, microRNA; TNM, tumor-node-metastasis.
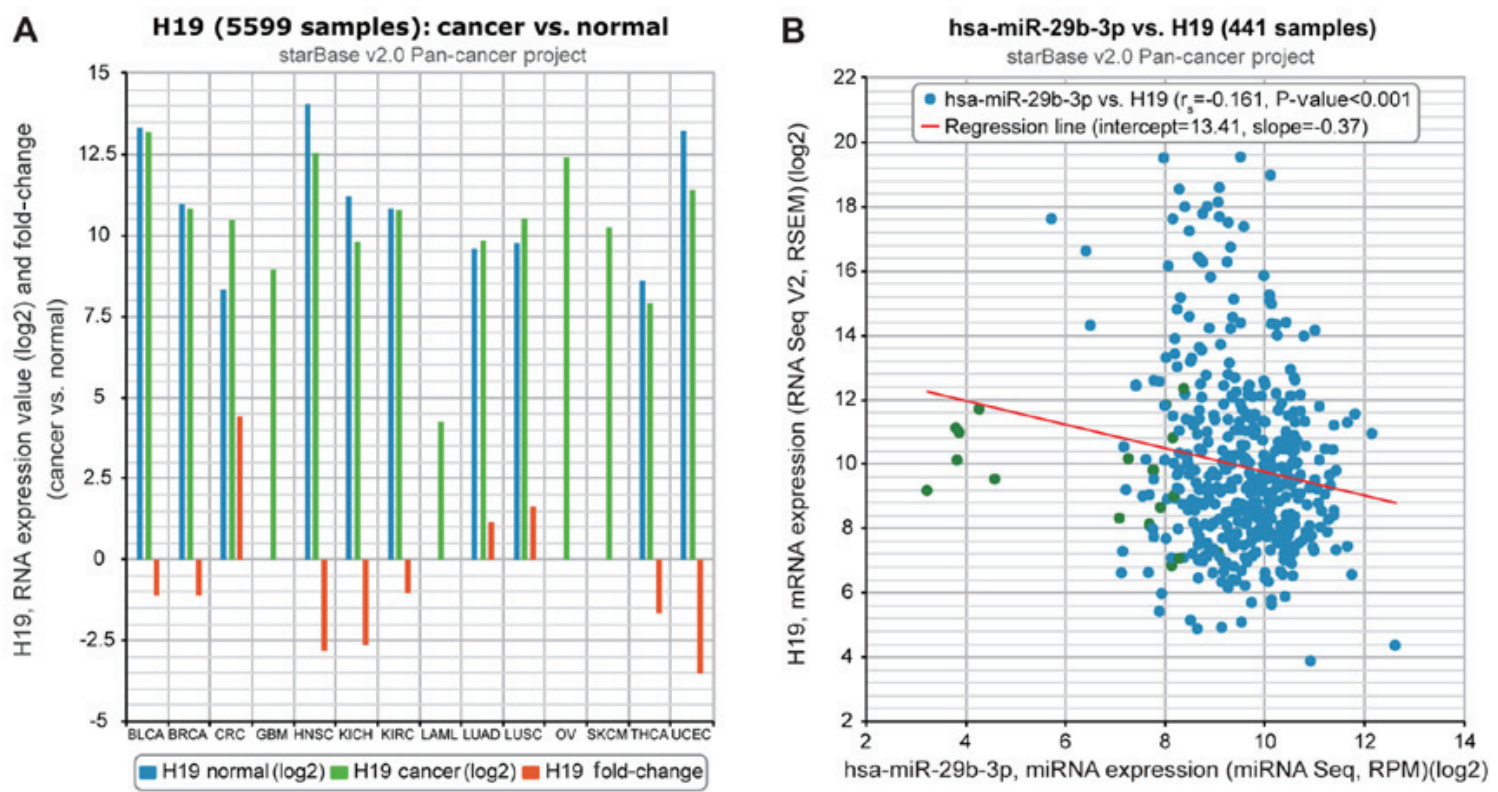

Figure 1. Relevance of H19 to miR-29b-3p on the basis of The Cancer Genome Atlas starBase (version 2.0) data portal. (A) H19 expression was compared between cancer and normal tissues. (B) H19 expression was negatively correlated with miR-29b-3p expression in lung adenocarcinoma tissues. miR/miRNA, microRNA; hsa, human; BLCA, bladder urothelial carcinoma; BRCA, breast cancer; CRC, colorectal cancer; GBM, glioblastoma multiforme; HNSC, head and neck squamous cell carcinoma; KICH, kidney chromophobe; KIRC, kidney renal clear cell carcinoma; LAML, acute myeloid leukemia; LUAD, lung adenocarcinoma; LUSC, lung squamous cell carcinoma; OV, ovarian cancer; SKCM, skin cutaneous melanoma; THCA, thyroid carcinoma; UCEC, uterine corpus endometrial carcinoma.

transfection with miR-29b-3p mimic and miR-29b-3p inhibitor, respectively $(\mathrm{P}<0.05$; Fig. $3 \mathrm{~B})$. In accordance with the results of CCK-8, flow cytometry and colony formation assays, the proliferation, viability and survival of Calu-3 and NCI-H1975 cell lines in the si-H19 group were significantly decreased, compared with those in the si-NC group $(\mathrm{P}<0.05$; Fig. 4A). Conversely, following transfection of pcDNA3.1-H19, the Calu-3 and NCI-H1975 cell lines exhibited significantly decreased apoptosis, along with significantly increased proliferation and viability, 

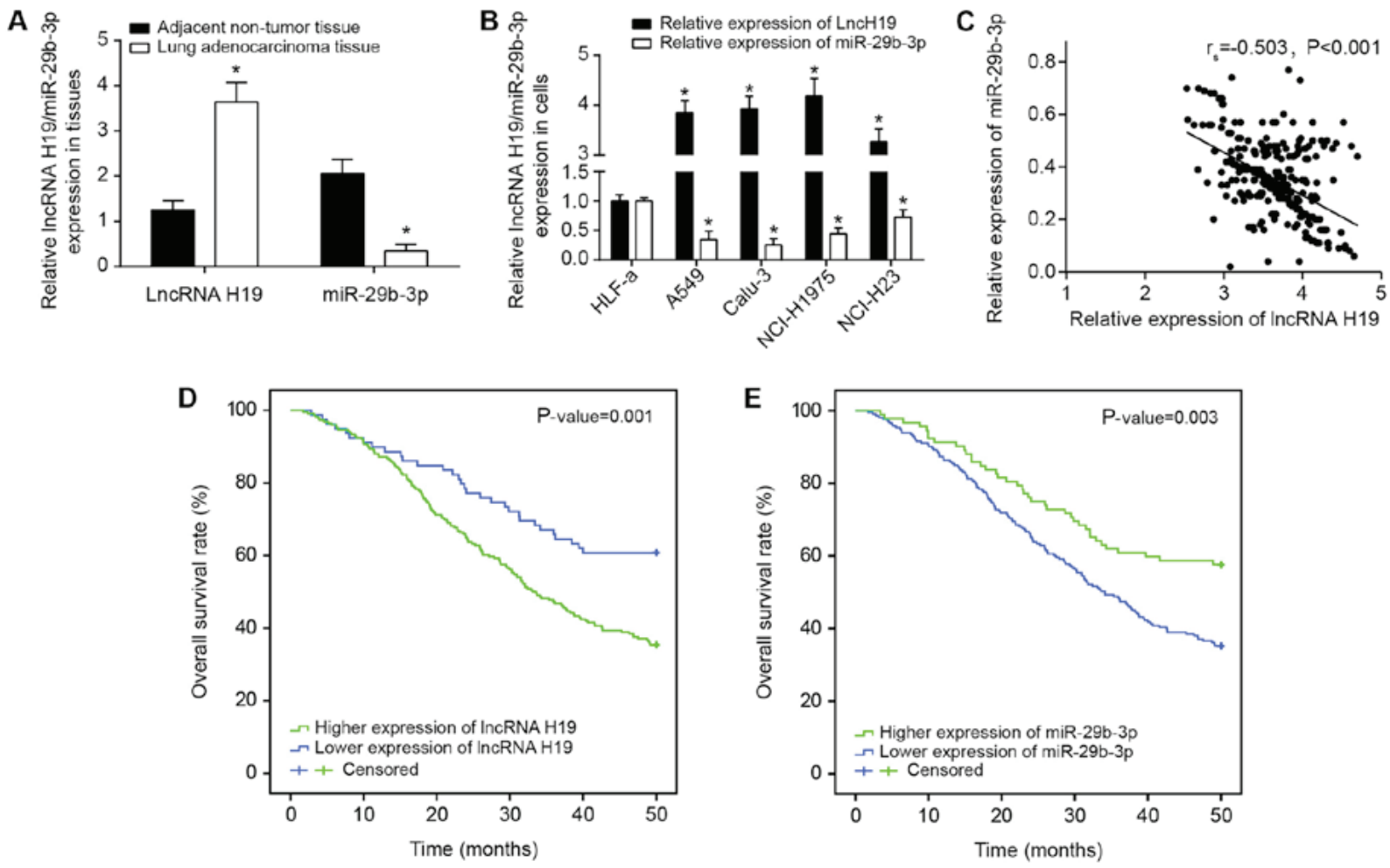

Figure 2. Expression of lncRNA H19 and miR-29b-3p were determined in lung adenocarcinoma tissues and cells. (A) H19 and miR-29b-3p expression were compared between lung adenocarcinoma tissues and adjacent normal tissues. ${ }^{\mathrm{P}}<0.05$ vs. adjacent normal tissues. (B) H19 and miR-29b-3p expression were compared in HLF-a, Calu-3, NCI-H1975, A549 and NCI-H23 cell lines. "P<0.05 vs. HLF-a cell line. (C) H19 expression was negatively correlated with miR-29b-3p expression in the collected lung adenocarcinoma tissues. (D) Increased H19 expression was associated with poor survival rates of patients with lung adenocarcinoma. (E) The patients with adenocarcinoma with increased higher miR-29b-3p expression had a better prognosis. IncRNA, long non-coding RNA; miR, microRNA.
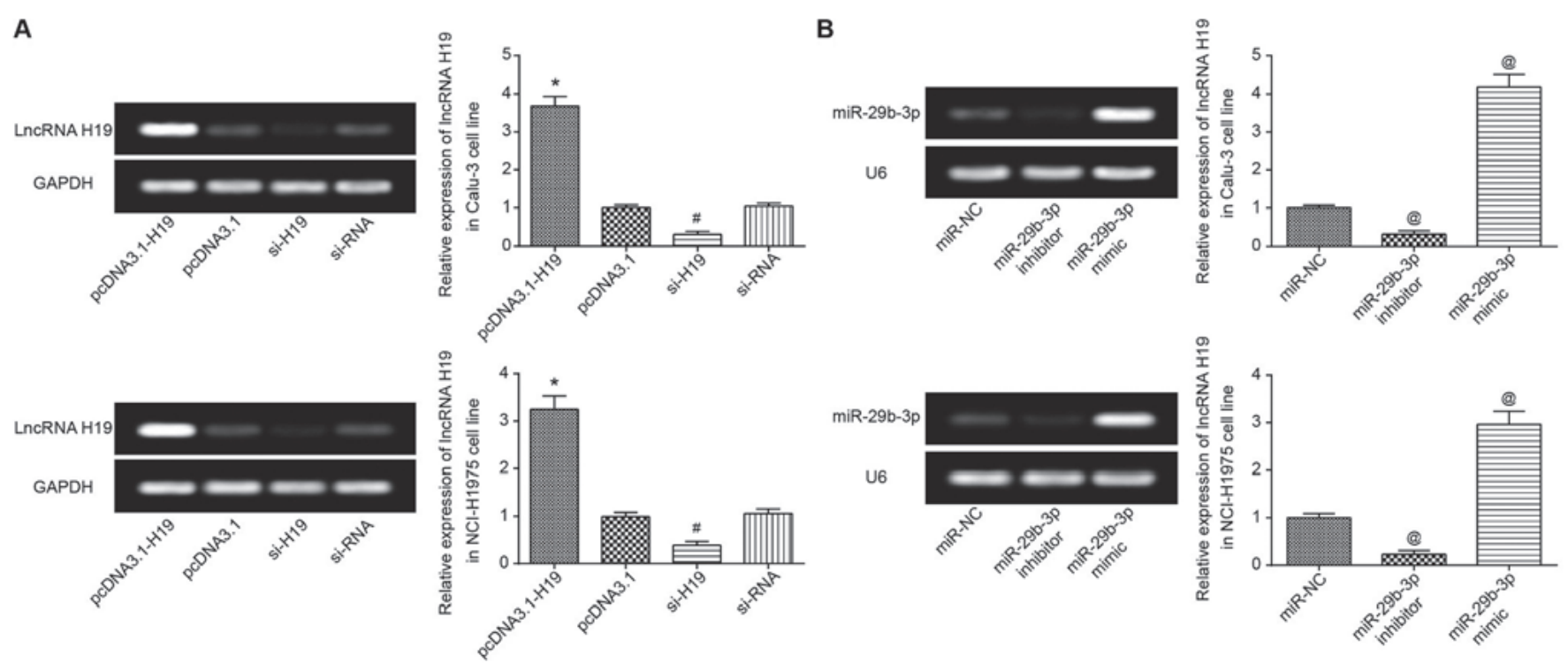

Figure 3. (A) H19 expression in Calu-3 and NCI-H1975 cells was determined following transfection with pcDNA3.1-H19 or si-H19. (B) miR-29b-3p expression was determined in Calu-3 and NCI-H1975 cells following transfection with miR-29b-3p mimic or miR-29b-3p inhibitor. " $\mathrm{P}<0.05$ vs. pcDNA3.1; ${ }^{\mathrm{P}} \mathrm{P}<0.05$ vs. si-NC. miR, microRNA; si, short interfering RNA; NC, negative control; lncRNA, long non-coding RNA.

when compared with the pcDNA3.1 group (all $\mathrm{P}<0.05$; Figs. 4 and 5A). In addition, with the NC group as the reference, the proliferative capacity and viability of Calu-3 and NCI-H1975 cell lines in the miR-29b-3p mimic group were significantly decreased, and the apoptotic percentage of the cells were significantly increased $(\mathrm{P}<0.05)$. By contrast, the miR-29b-3-p inhibitor group exhibited significantly increased proliferation and viability, as well as a significantly decreased percentage of apoptotic cells in comparison with the control group $(\mathrm{P}<0.05$; Figs. 4 and $5 \mathrm{~A})$. 

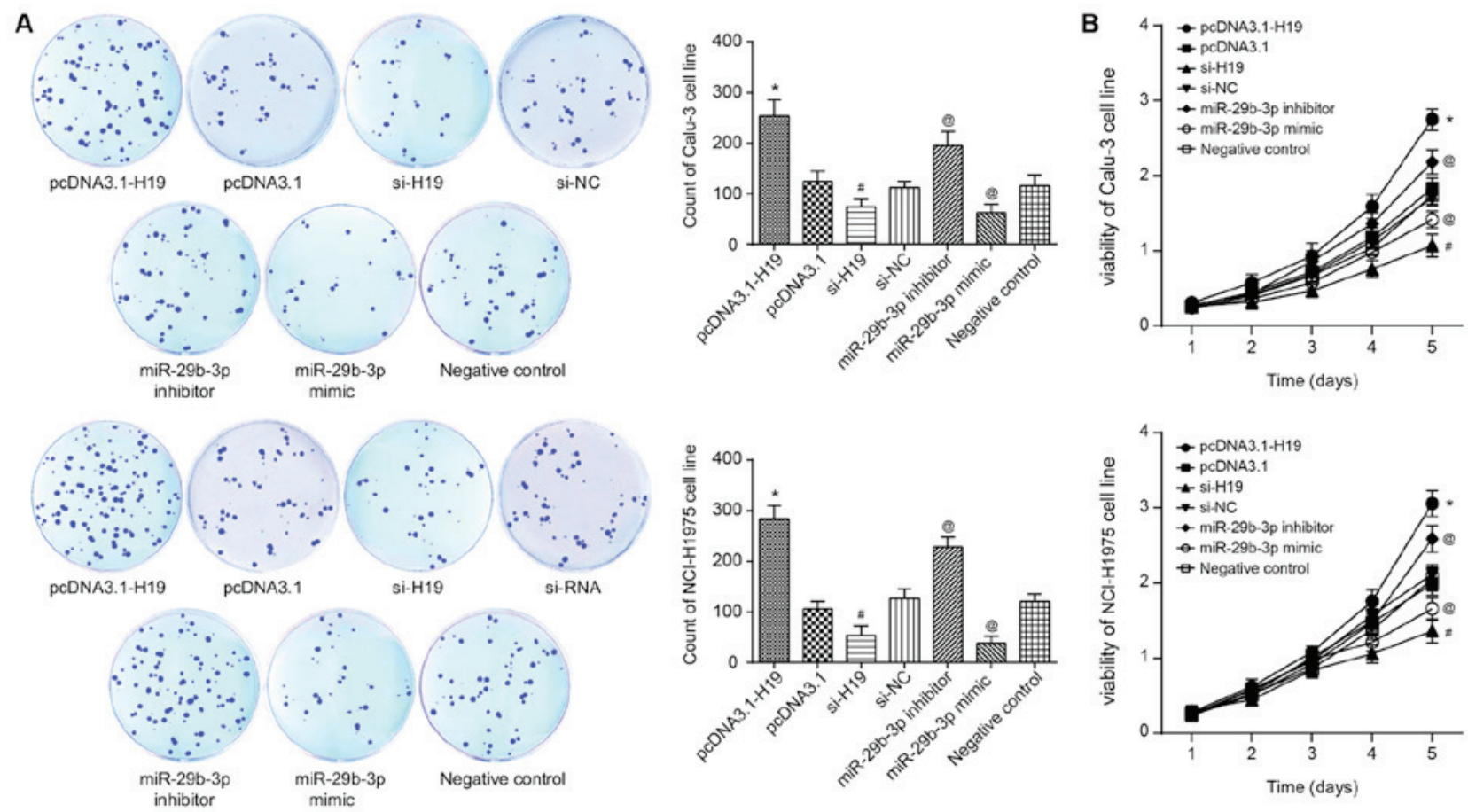

Figure 4. (A) Proliferation and (B) viability were compared among pcDNA3.1-H19-, pcDNA3.1-, si-H19-, si-NC-, miR-29b-3p inhibitor-, miR-29b-3p mimicand negative control-transfected Calu-3 and NCI-H1975 cell lines. ${ }^{*} \mathrm{P}<0.05$ vs. pcDNA $3.1 ;{ }^{~} \mathrm{P}<0.05$ vs. si-NC; ${ }^{\circledR} \mathrm{P}<0.05$ vs. negative control. si, short interfering; NC, negative control; miR, microRNA.

H19 and miR-29b-3p modify the expression of EMT-specific proteins in lung adenocarcinoma cells. As the western blot results indicated, the expression of epithelial marker (i.e. E-cadherin) in the miR-29b-3p mimic group was increased significantly $(\mathrm{P}<0.05)$, whereas the expression of interstitial markers, including vimentin, Snail and Slug, was significantly decreased $(\mathrm{P}<0.05)$ in the Calu-3 and NCI-H1975 cell lines (Fig. 5B). Distinct from the miR-29b-3p mimic group, Calu-3 and NCI-H1975 cells of the miR-29b-3p inhibitor group were observed with significantly increased vimentin, Snail and Slug expression, as well as significantly decreased E-cadherin expression $(\mathrm{P}<0.05$; Fig. 5B). Furthermore, the decrease in H19 expression in Calu-3 and NCI-H1975 cell lines induced a significant decrease in vimentin, Snail and Slug expression, and a significant increase in E-cadherin expression $(\mathrm{P}<0.05$; Fig. 5B).

H19 targets miR-29b-3p to decrease its expression. It was predicted using starBase software that H19 could target miR-29b-3p at chr11: 2017218-2017240 and chr11: 2017218-2017320 (Fig. 6A). Furthermore, the dual-luciferase reporter gene assay conducted utilizing Calu-3 and NCI-H1975 cell lines indicated that transfection of pmirGLO-H19-Wt and miR-29b-3p mimic could induce significantly decreased luciferase activity compared with cells transfected with pmirGLO-H19-Wt and miR-NC $(\mathrm{P}<0.05$; Fig. 6B). No evident difference in luciferase activity of the pmirGLO-H19-Mut+miR-29b-3p mimic group from that of pmirGLO-H19-Wt+miR-NC group was observed. Furthermore, RT-qPCR results indicated that increased H19 expression may significantly decrease the expression level of miR-29b-3p in Calu-3 and NCI-H1975 cell lines $(\mathrm{P}<0.05$; Fig. 6C). However, there was limited effect on H19 expression, whether miR-29b-3p expression was increased or decreased $(\mathrm{P}<0.05)$ (Fig. 6D).

STAT3 is modified by miR-29b-3p in lung adenocarcinoma cells. STAT3 expression in lung adenocarcinoma cells was positively correlated with $\mathrm{H} 19$ expression $(\mathrm{P}<0.05)$, yet it appeared to be negatively correlated with miR-29b-3p expression $(\mathrm{P}<0.05)$ (Fig. 7A). In addition, overexpressed H19 and underexpressed miR-29b-3p could contribute to abnormally overexpressed STAT3 in Calu-3 and NCI-H1975 cell lines $(\mathrm{P}<0.05$; Fig. 7B). Furthermore, the luciferase activity of miR-29b-3p mimic binding to pmirGLO-STAT3-Wt was significantly increased compared with that in cells co-transfected with miR-29b-3p mimic and pmirGLO-STAT3-Mut $(\mathrm{P}<0.05)$, and the latter revealed luciferase activity that was not significantly different from that of the pmirGLO-STAT3-Wt+miR-NC group (Fig. 7C).

STAT3 is modified by $H 19$ and miR-29b-3p in altering viability, proliferation and apoptosis of lung adenocarcinoma cells, as well as the EMT-specific proteins in lung adenocarcinoma cells. It was observed that the proliferation and viability of Calu-3 and NCI-H1975 cell lines in the miR-NC+STAT3 group were significantly increased compared with those of the miR-NC group (P<0.05; Fig. 8), and the apoptotic rate of the miR-NC+STAT3 group was below that of miR-NC group ( $\mathrm{P}<0.05$; Fig. 9A). Regarding the expression of EMT-specific proteins, it was identified that the miR-NC+STAT3 group significantly increased vimentin, Snail and Slug expression, as well as decreased E-cadherin expressions, when compared with miR-NC group $(\mathrm{P}<0.05$; Fig. 9B). These results therefore suggested that STAT3 inhibits the effect of miR-29b-3p on the viability, proliferation, apoptosis and EMT of lung adenocarcinoma cells. 
A

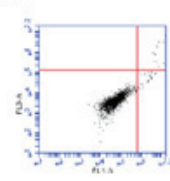

pCDNA3.1-H19

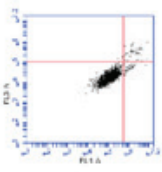

PCDNA3.1

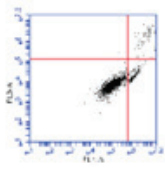

si-H19

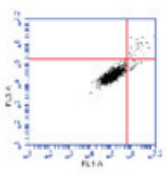

PCDNA3.1
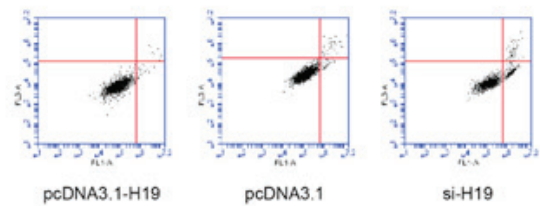

si-H19
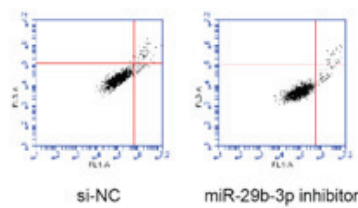

miR-29b-3p inhibitor
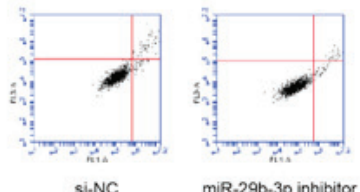

miR-29b-3p inhibitor

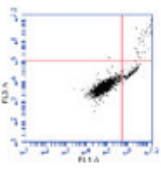

miR-29b-3p mimic
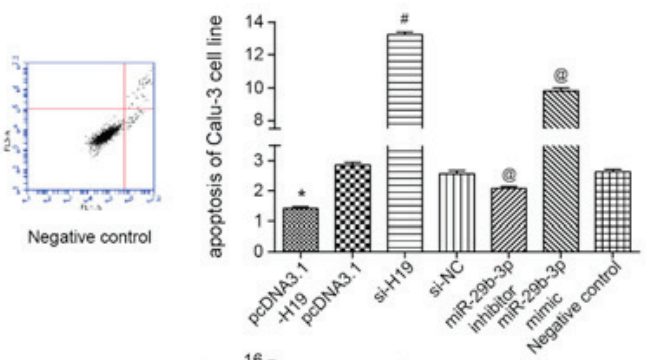

si-NC

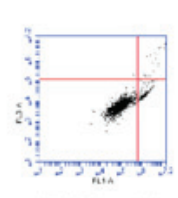

miR-29b-3p mimic
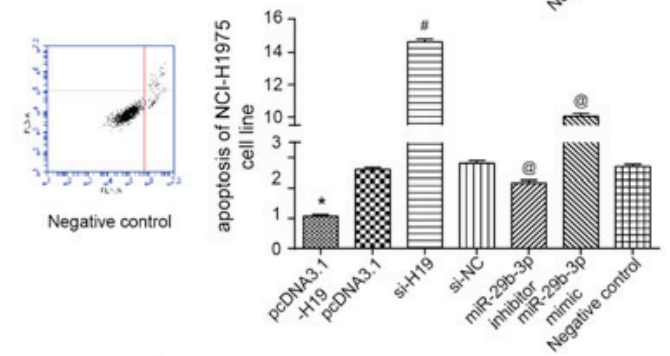

B
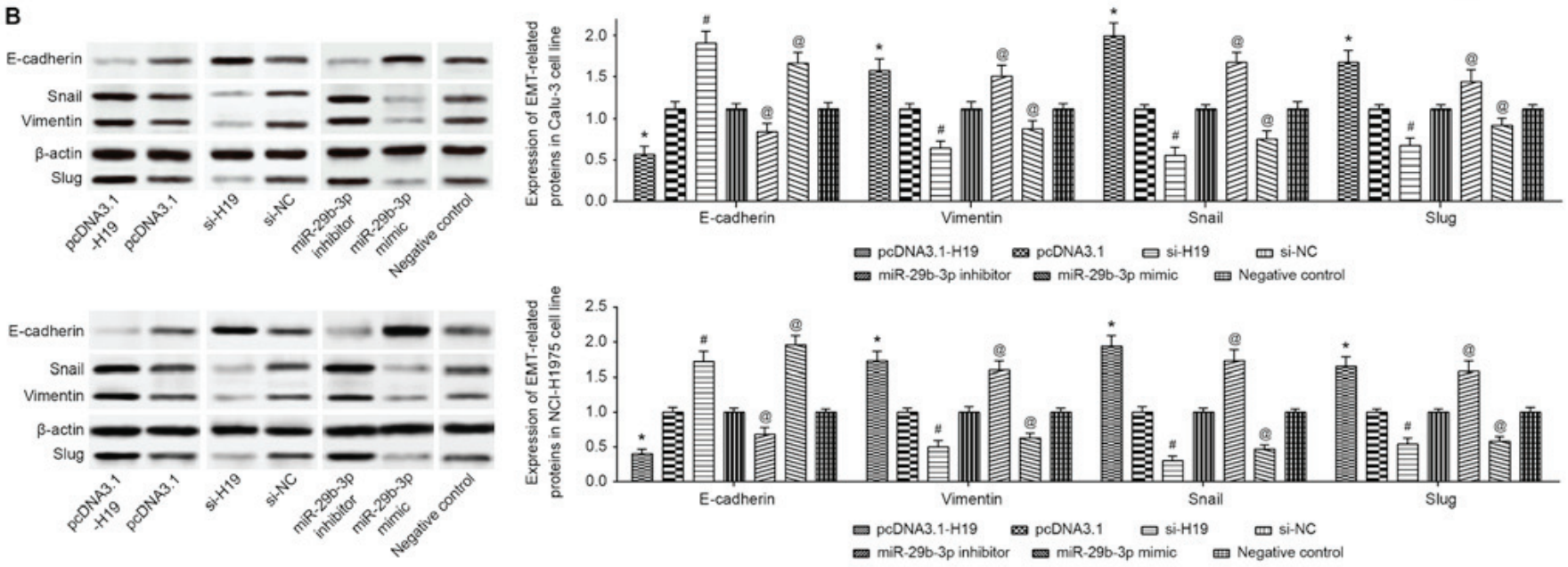

Figure 5. (A) Apoptotic status and (B) EMT protein expression were compared among pcDNA3.1-H19-, pcDNA3.1-, si-H19-, si-NC-, miR-29b-3p inhibitor-, miR-29b-3p mimic- and negative control-transfected Calu-3 and NCI-H1975 cell lines. ${ }^{*} \mathrm{P}<0.05$ vs. pcDNA3.1; ${ }^{\mathrm{P}}<0.05$ vs. si-NC; ${ }^{\circledR} \mathrm{P}<0.05$ vs. negative control. In (B), the spaces between lanes marked by pcDNA3.1 and si-H19, as well as between lanes marked by si-NC and miR-29b-3p inhibitor indicate that the samples were run on different gels. Other spaces between lanes and between rows indicate that irrelevant lanes have been excised. EMT, epithelial-mesenchymal transition; si, short interfering RNA; NC, negative control; miR, microRNA; E-cadherin, epithelial cadherin.

\section{Discussion}

Primary bronchial carcinoma, also known as lung cancer, is a major cause of mortality $(30,31)$, and the prevalence of its one pathological pattern (i.e. lung adenocarcinoma) is increasing (32). Although traditional therapies for lung adenocarcinoma, such as surgery, chemotherapy and radiotherapy, have been performed, 5-year survival rate of patients remains low at $\sim 10 \%$ (2). Among them, resistance to chemotherapies appears to be the factor limiting the recovery of patients with lung adenocarcinoma patients, and certain lncRNAs and miRNAs have been identified to participate in the underlying molecular mechanism $(33,34)$. Notably, alterations in cell viability, survival, apoptosis and EMT proteins may also guide the chemoresistance of tumor cells in a different direction. Thus, in the present study, the role of lncRNA H19 and miR-29b-3p in regulating EMT, viability and apoptosis of lung carcinoma cells was investigated.

H19 was initially identified by Bartolomei et al in 1991 (35), and it was revealed to underlie the development process of bladder carcinoma, hepatocellular carcinoma, breast cancer and lung cancer (35-38). For example, H19 expressed in NSCLC tissues was increased 2 -fold compared with in adjacent normal tissues $(39,40)$. The present study also revealed similar results, and it also demonstrated that patients with lung adenocarcinoma with higher H19 expression exhibited an increased survival rate compared with those with lower H19 expression. With regard to the in vitro experiments, H19 was revealed to promote metastasis and proliferation of lung adenocarcinoma cells, which led to decreased sensitivity of the cells to cisplatin (40). Similar to this result, the present study also revealed that upregulated H19 expression could increase cell viability, cell proliferation and expression of EMT-specific proteins in cells, as well as decrease cell apoptosis. Of note, a previous study identified that the $\mathrm{H} 19$ promoter intensified by c-myc could facilitate the proliferation of lung cancer cells by increasing miR-107 expression (39). In the present study, it was identified that $\mathrm{H} 19$ could suppress miR-29b-3p expression in lung carcinoma cells, which also resulted in increased viability and proliferation, along with decreased apoptosis of the neoplastic cells. It was thus suggested that H19 may interact with various miRNAs to modify the activity of lung 
A

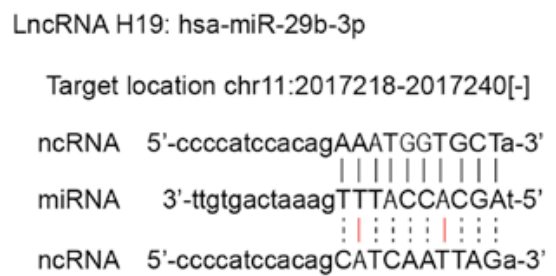

LncRNA H19: hsa-miR-29b-3p

Target location chr11:2017218-2017320[-]

ncRNA 5'-acaacatgaaagAAATGGTGCTa-3'

miRNA 3'-ttgtgactaaagTTTACCACGAt-5'

ncRNA 5'-acaacatgaaag CCCTATGACGa-3'
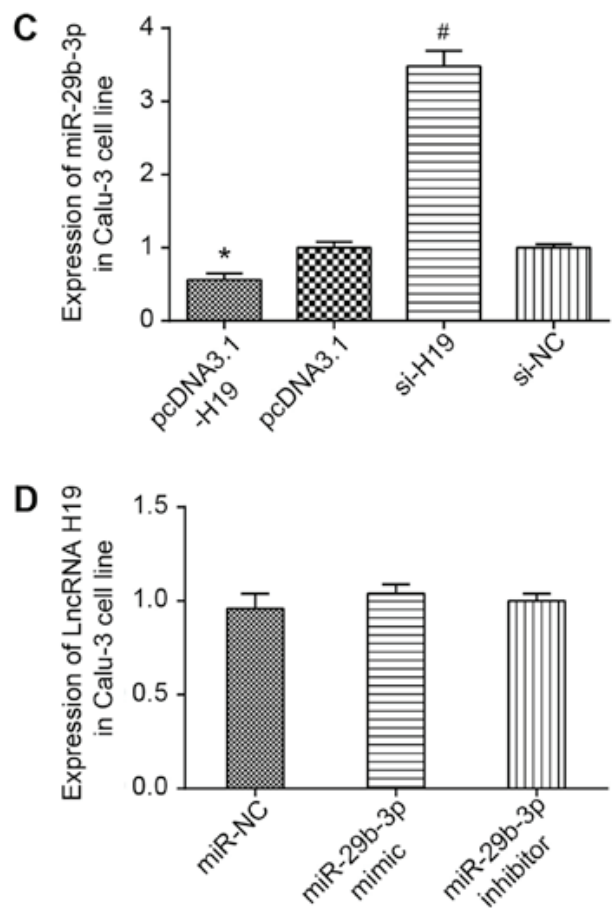
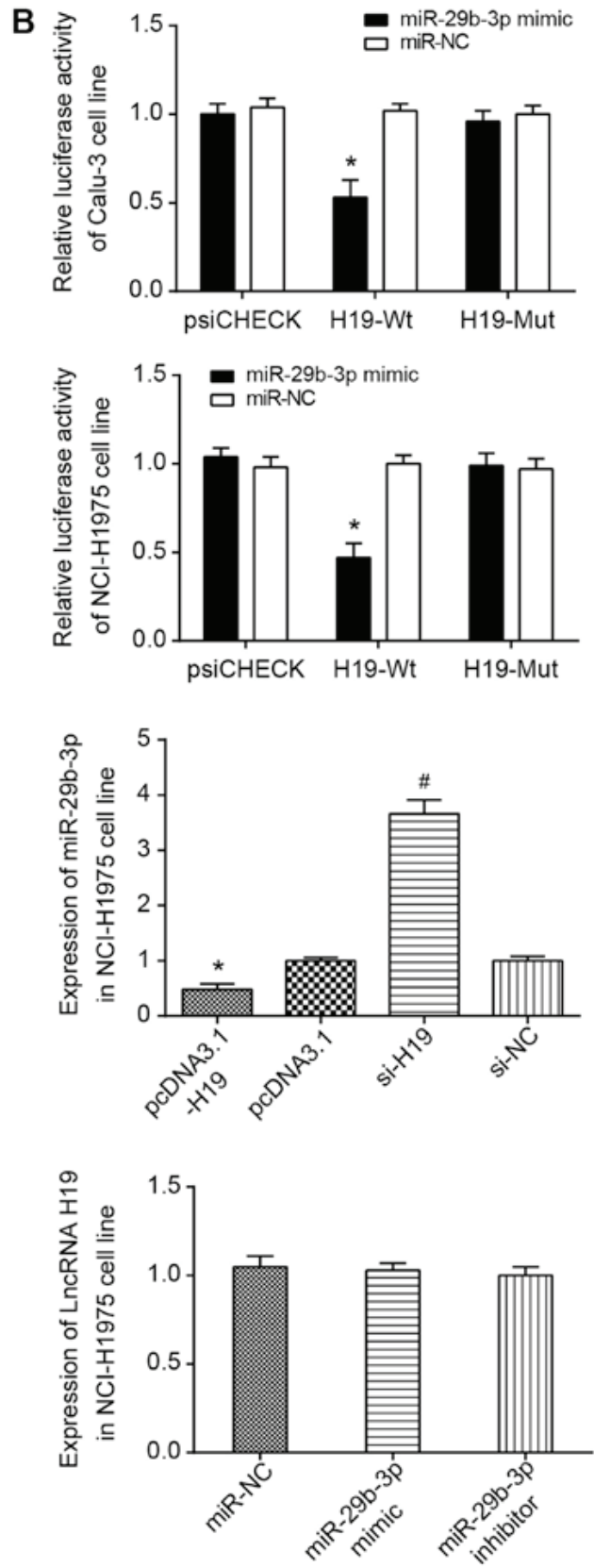

Figure 6. Association between H19 and miR-29b-3p. (A) H19 is targeted by miR-29b-3p in chr11: 2017218-2017240 and chr11: 2017218-2017320. (B) Luciferase activities in Calu-3 and NCI-H1975 cell lines were compared between miR-29b-3p mimic $+\mathrm{H} 19-\mathrm{Wt}$ and miR-29b-3p mimic $+\mathrm{H} 19-\mathrm{Mut}$ groups. ${ }^{*} \mathrm{P}<0.05$ vs. miR-29b-3p mimic+H19-Mut group. (C) Effects of H19 on miR-29b-3p expression were determined in Calu-3 and NCI-H1975 cell lines. "P<0.05 vs. pcDNA3.1; ${ }^{\#} \mathrm{P}<0.05$ vs. si-NC. (D) Influence of miR-29b-3p on $\mathrm{H} 19$ expression was determined in Calu-3 and NCI-H1975 cell lines. "P<0.05 vs. negative control. miR/ miRNA, microRNA; si, short interfering RNA; NC, negative control; ncRNA, non-coding RNA; lncRNA, long non-coding RNA; hsa, human.

adenocarcinoma cells, and other downstream molecules require further investigation. Nevertheless, the present study was limited by not establishing mouse models to verify the effects of H19 and miR-29b-3p on the progression of lung adenocarcinoma, as in a previous study (41). One point that should be underlined is how $\mathrm{H} 19$ acts on miR-29b-3p to regulate the development of lung adenocarcinoma. Salmena et al (19) proposed a competing endogenous RNA hypothesis that mRNAs, pseudogenes, IncRNAs and other endogenous RNAs could competitively combine with the same miRNA with their specific miRNA-binding sites, thereby limiting the inhibitory effect of miRNA on the mRNA of target genes and increasing the expression of target genes. Consistent with this hypothesis, the present study also identified that $\mathrm{H} 19$ had a 'sponging' function (42), and H19 could target miR-29b-3p to limit its expression. In addition, the aforementioned miR-29b was previously identified to participate in the modulation of cell apoptosis, the cell cycle and cell metastasis $(43,44)$. In particular, abnormally increased expression of miR-29b decreased the proliferation, migration and invasion of lung cancer cells by $<30 \%$ (45). Furthermore, miR-29b-3p expression was significantly decreased in pancreatic carcinoma cells when compared with in normal cells, and upregulation of miR-29b-3p expression could significantly limit proliferation of the cells (46). These results were verified in the present study, and it was concluded that miR-29b-3p, which was 
A
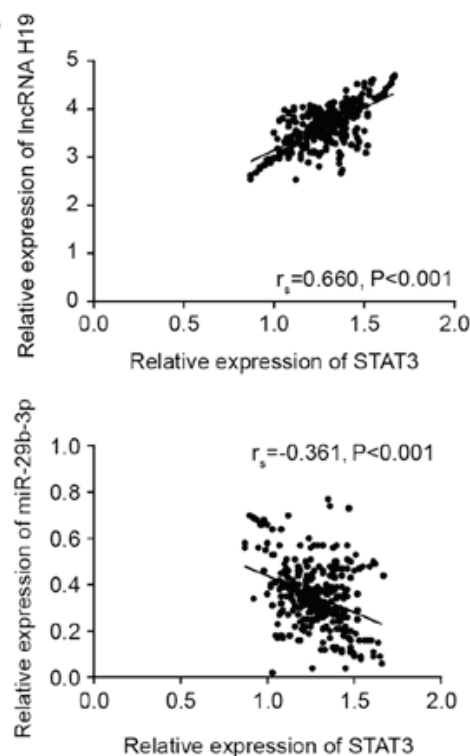

C

STAT3: hsa-miR-29b

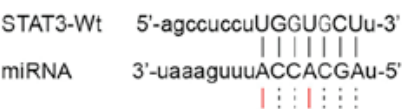

B

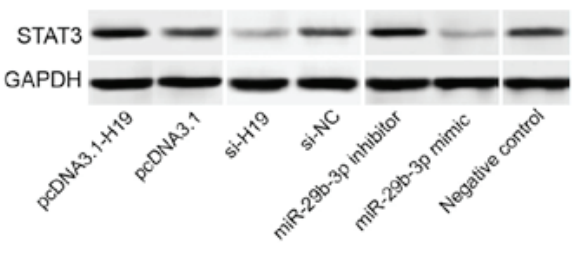

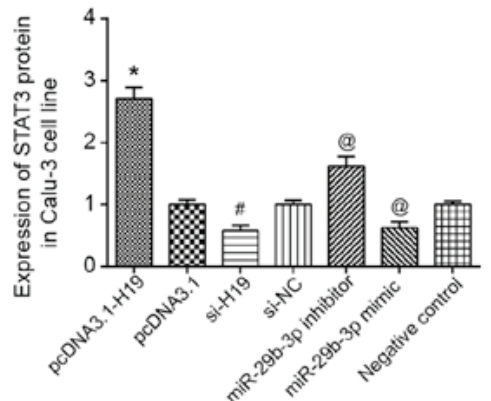
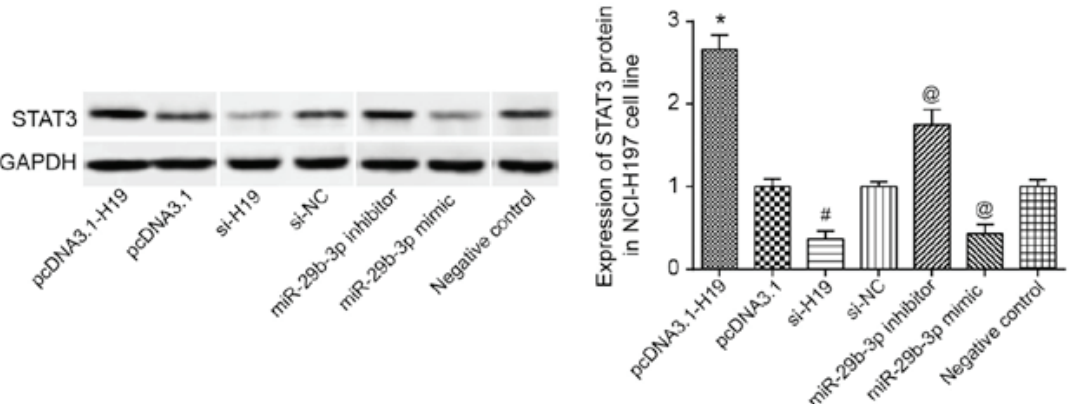

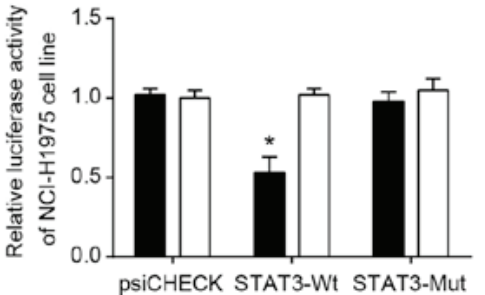

Figure 7. Association between miR-29b-3p and STAT3. (A) H19 expression was positively correlated with STAT3 expression in lung adenocarcinoma tissues. miR-29b-3p expression was negatively correlated with STAT3 expression in lung adenocarcinoma tissues. (B) STAT3 expression in pcDNA3.1-H19-, pcDNA3.1-, si-H19-, si-NC-, miR-29b-3p inhibitor-, miR-29b-3p mimic- and negative control-transfected Calu-3 and NCI-H1975 cell lines. "P<0.05 vs. pcDNA3.1; ${ }^{~} \mathrm{P}<0.05$ vs. si-NC; ${ }^{\circledR} \mathrm{P}<0.05$ vs. negative control. Spaces between lanes marked by pcDNA3.1 and si-H19, as well as between lanes marked by si-NC and miR-29b-3p inhibitor indicate that the samples were run on different gels. Other spaces between lanes and between rows indicate that irrelevant lanes have been excised. (C) miR-29b-3p targeted STAT3 in certain sites. The luciferase activities of Calu-3 and NCI-H1975 cell lines were compared between miR-29b-3p mimic+STAT3-Wt and miR-29b-3p mimic+STAT3-Mut groups."P<0.05 vs. miR-29b-3p mimic+STAT3-Mut group. miR/miRNA, microRNA; STAT3, signal transducer and activator of transcription 3; si, short interfering; NC, negative control; lncRNA, long non-coding RNA; hsa, human.

A
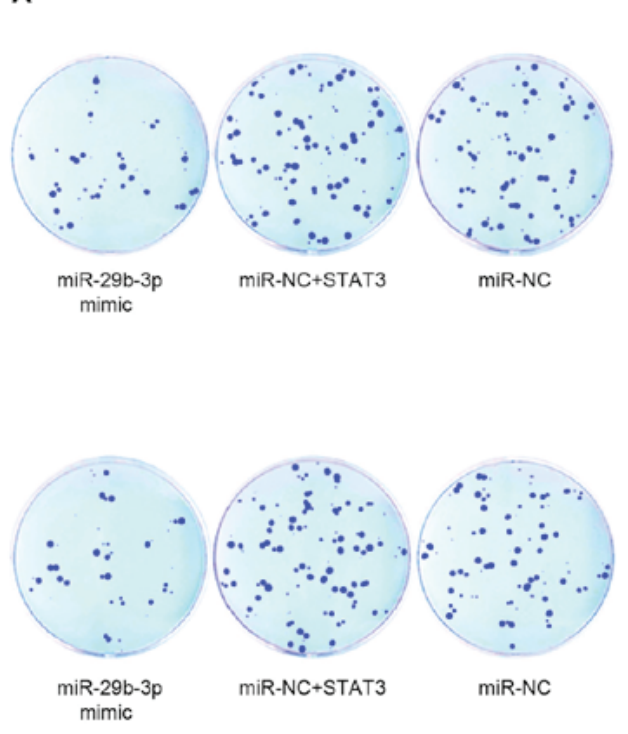
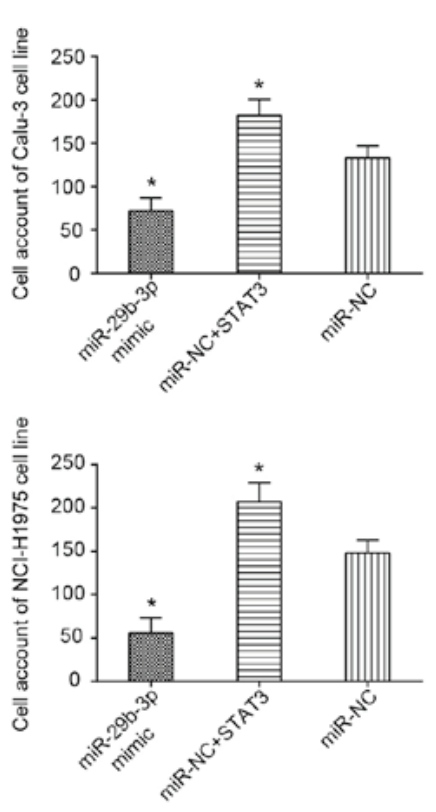
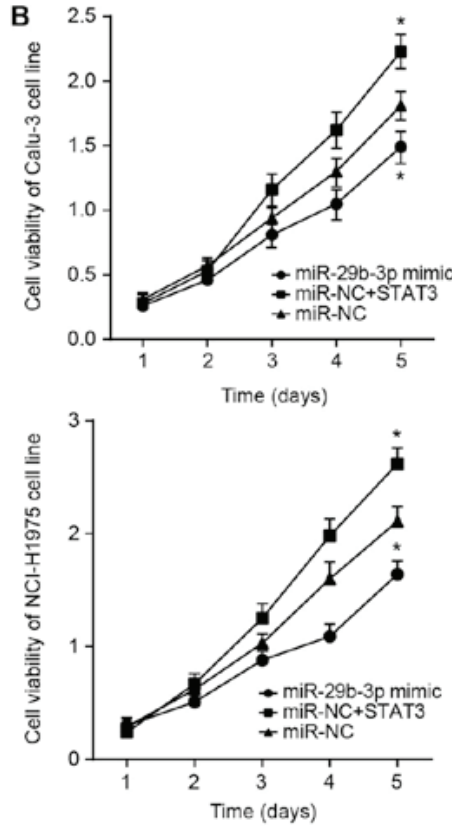

Figure 8. (A) Colony formation and (B) Cell Counting Kit-8 assays were performed to determine the proliferative capacity and viability of Calu-3 and NCI-H1975 cell lines among miR-NC, miR-29b-3p mimic and miR-NC+STAT3 groups. "P<0.05 vs. miR-29b-3p. miR, microRNA; NC, negative control; STAT3, signal transducer and activator of transcription 3. 
A
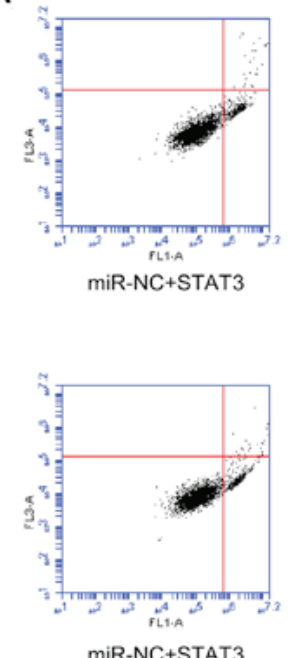

miR-NC+STAT3

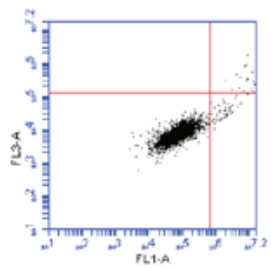

miR-29b-3p mimic

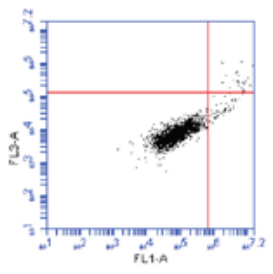

miR-29b-3p mimic

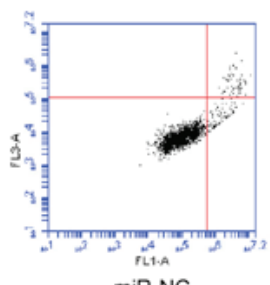

miR-NC

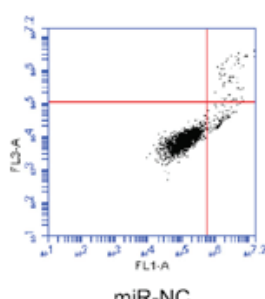

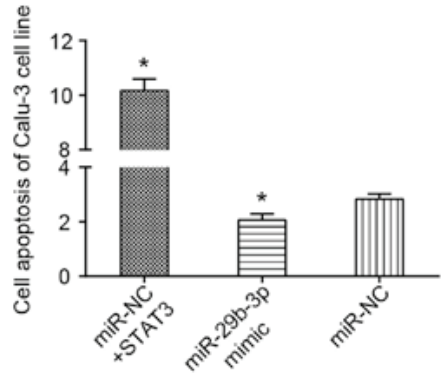

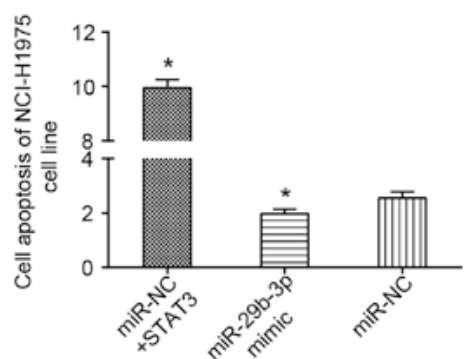

B
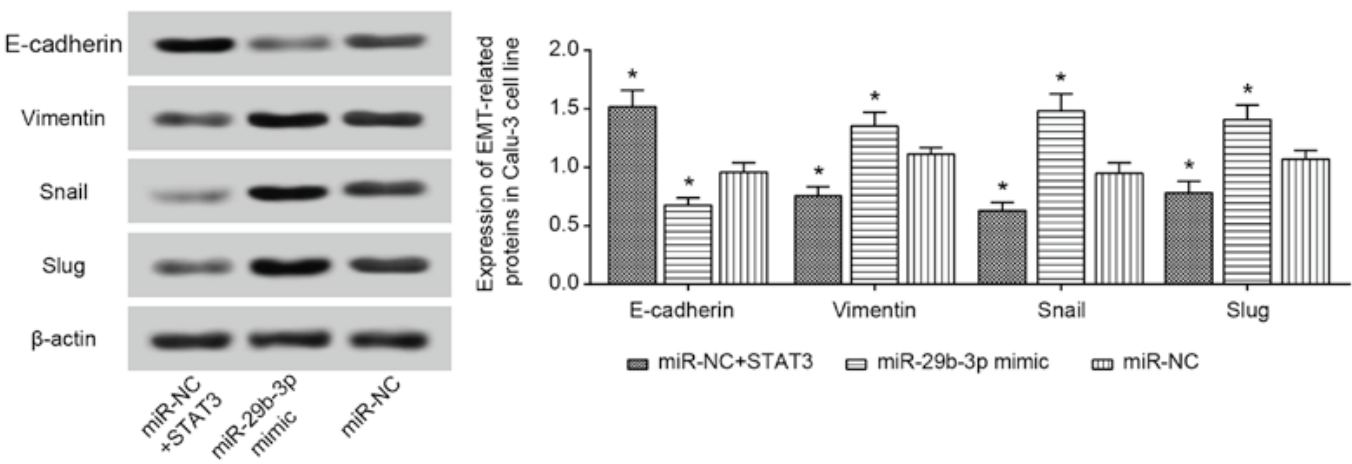

$\square$ miR-NC+STAT3 घ miR-29b-3p mimic m miR-NC
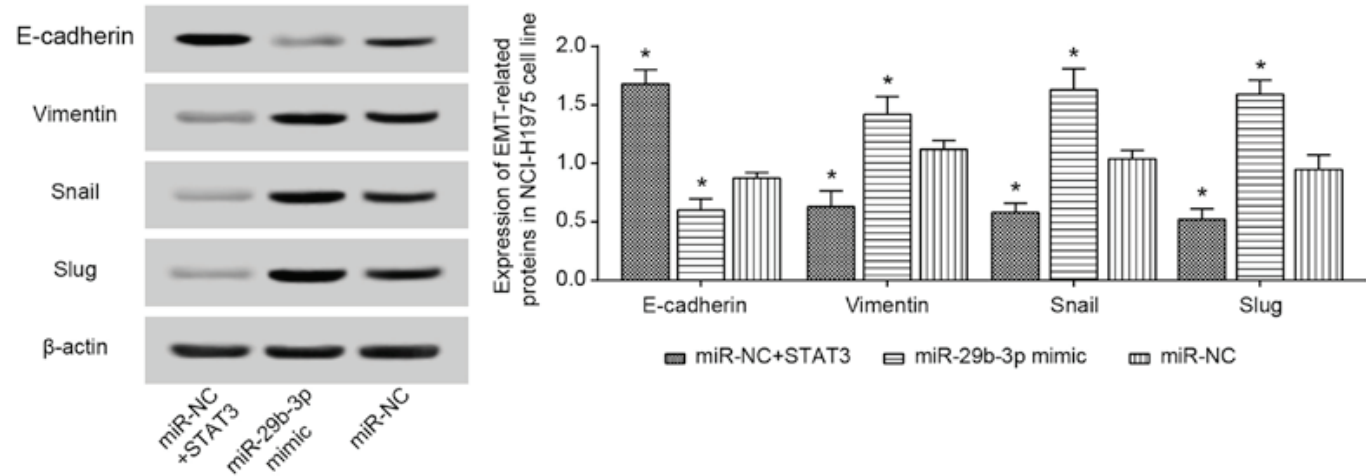

$\square$ miR-NC+STAT3 घ miR-29b-3p mimic m miR-NC

Figure 9. (A) Determination of apoptosis and (B) expression of EMT proteins (i.e. E-cadherin, vimentin, Snail and Slug) in Calu-3 and NCI-H1975 cell lines was assessed among miR-NC, miR-29b-3p mimic and miR-NC+STAT3 groups. ${ }^{*} \mathrm{P}<0.05$ vs. miR-29b-3p. EMT, epithelial-mesenchymal transition; E-cadherin, epithelial cadherin; miR, microRNA; STAT3, signal transducer and activator of transcription 3; NC, negative control.

regulated by $\mathrm{H} 19$, could suppress proliferation, viability and EMT, and promote the apoptosis of lung carcinoma cells.

In addition, the present study also indicated that STAT3 was the target gene of miR-29b-3p, and miR-29b-3p could directly regulate STAT3 expression. As a component of the Janus kinase signaling pathway, STAT3 appears to be critical for cancer onset and progression in the tumor microenvironment $(47,48)$. More specifically, activation of STAT3 usually either increased cell proliferation and survival or decreased cell apoptosis (49,50). Consistently, the present study indicated that the STAT3 activated by H19 and miR-29b-3p allowed increased proliferation and decreased apoptosis of the lung adenocarcinoma cells, as well as activated EMT-specific protein expression in the cells. As for whether
H19, miR-29b-3p and STAT3 could alter metastasis of lung adenocarcinoma cells via induction of the EMT process (51), further investigation is required.

In summary, the H19/miR-29b-3p/STAT3 axis could affect EMT, apoptosis, proliferation and viability of lung carcinoma cells, which potentially reveals the underlying molecular mechanism of lung adenocarcinoma. The results may provide a foundation for developing a complete strategy for diagnosing and treating lung carcinoma. However, the present study was limited by the small size of the clinical samples analyzed, which may not be applicable to the wider population. Furthermore, relevant animal models to validate the study results were not established. Thirdly, since the progression of lung adenocarcinoma resulted from mixed effects of 
various genes, additional downstream and upstream genes require investigation. In addition, although it is hypothesized that H19 and miR-29b-3p may function to interfere with the chemosensitivity of lung adenocarcinoma cells on the basis of their molecular mechanisms, to the best of our knowledge, this has not been investigated. Finally, since there are limited standards formulated to unify the results of diverse methods, there may be misunderstanding when experimental results that were focused on one point were compared, such as detection methods for lncRNAs. Therefore, further in-depth investigations are still required.

\section{Acknowledgements}

Not applicable.

\section{Funding}

Not applicable.

\section{Availability of data and materials}

The datasets used and analyzed during the current study are available from the corresponding author on reasonable request.

\section{Authors' contributions}

LihL, LinL and SL conceived and designed the experiments. LihL, LinL and SL performed the experiments. LihL and LinL analyzed the data. SL drafted the manuscript. All authors have read and approved the final manuscript.

\section{Ethics approval and consent to participate}

The present study was approved by the Ethics Committee of The First Affiliated Hospital of Jinzhou Medical University (Jinzhou, China) and all patients provided written informed consent.

\section{Patient consent for publication}

Not applicable.

\section{Competing interests}

The authors declare that they have no competing interests.

\section{References}

1. Wistuba II: Genetics of preneoplasia: Lessons from lung cancer. Curr Mol Med 7: 3-14, 2007.

2. Verdecchia A, Francisci S, Brenner H, Gatta G, Micheli A, Mangone L and Kunkler I; EUROCARE-4 Working Group: Recent cancer survival in Europe: A 2000-02 period analysis of EUROCARE-4 data. Lancet Oncol 8: 784-796, 2007.

3. Klebe S and Henderson DW: Facts and fiction: Premalignant lesions of lung tissues. Pathology 45: 305-315, 2013.

4. Djebali S, Davis CA, Merkel A, Dobin A, Lassmann T, Mortazavi A, Tanzer A, Lagarde J, Lin W, Schlesinger F, et al: Landscape of transcription in human cells. Nature 489: 101-108, 2012.

5. Gadgeel SM, Cote ML, Schwartz AG, Matherly LH, Wozniak A and Bepler G: Parameters for individualizing systemic therapy in non-small cell lung cancer. Drug Resist Updat 13: 196-204, 2010.
6. Birney E, Stamatoyannopoulos JA, Dutta A, Guigó R, Gingeras TR, Margulies EH, Weng Z, Snyder M, Dermitzakis ET, Thurman RE, et al; Children's Hospital Oakland Research Institute: Identification and analysis of functional elements in $1 \%$ of the human genome by the ENCODE pilot project. Nature 447: 799-816, 2007.

7. Ponting CP and Belgard TG: Transcribed dark matter: Meaning or myth? Hum Mol Genet 19: R162-R168, 2010.

8. Inamura K: Major tumor suppressor and oncogenic non-coding RNAs: Clinical relevance in lung cancer. Cells 6: 6, 2017.

9. Shi T, Gao G and Cao Y: Long noncoding RNAs as novel biomarkers have a promising future in cancer diagnostics. Dis Markers 2016: 9085195, 2016.

10. Fatima R, Akhade VS, Pal D and Rao SM: Long noncoding RNAs in development and cancer: Potential biomarkers and therapeutic targets. Mol Cell Ther 3: 5, 2015.

11. Gayen S, Maclary E, Buttigieg E, Hinten M and Kalantry S: A primary role for the Tsix lncRNA in maintaining random X-chromosome inactivation. Cell Reports 11: 1251-1265, 2015.

12. Kawaguchi T and Hirose T: Chromatin remodeling complexes in the assembly of long noncoding RNA-dependent nuclear bodies. Nucleus 6: 462-467, 2015.

13. Zhuang W, Ge X, Yang S, Huang M, Zhuang W, Chen P, Zhang X, Fu J, Qu J and Li B: Upregulation of lncRNA MEG3 promotes osteogenic differentiation of mesenchymal stem cells from multiple myeloma patients by targeting BMP4 transcription. Stem Cells 33: 1985-1997, 2015.

14. Schmidt LH, Spieker T, Koschmieder S, Schäffers S, Humberg J, Jungen D, Bulk E, Hascher A, Wittmer D, Marra A, et al: The long noncoding MALAT-1 RNA indicates a poor prognosis in non-small cell lung cancer and induces migration and tumor growth. J Thorac Oncol 6: 1984-1992, 2011.

15. Lee YS and Dutta A: MicroRNAs: Small but potent oncogenes or tumor suppressors. Curr Opin Investig Drugs 7: 560-564, 2006.

16. Zhang E, Li W, Yin D, De W, Zhu L, Sun S and Han L: c-Myc-regulated long non-coding RNA H19 indicates a poor prognosis and affects cell proliferation in non-small-cell lung cancer. Tumour Biol 37: 4007-4015, 2016.

17. Sadiq AA and Salgia R: MET as a possible target for non-small-cell lung cancer. J Clin Oncol 31: 1089-1096, 2013.

18. Matouk IJ, Raveh E, Abu-lail R, Mezan S, Gilon M, Gershtain E, Birman T, Gallula J, Schneider T, Barkali M, et al: Oncofetal H19 RNA promotes tumor metastasis. Biochim Biophys Acta 1843: 1414-1426, 2014.

19. Salmena L, Poliseno L, Tay Y, Kats L and Pandolfi PP: A ceRNA hypothesis: The Rosetta Stone of a hidden RNA language? Cell 146: 353-358, 2011

20. Zaleska K: miRNA - Therapeutic tool in breast cancer? Where are we now? Rep Pract Oncol Radiother 20: 79-86, 2014.

21. Zhou W, Ye XL, Xu J, Cao MG, Fang ZY, Li LY, Guan GH, Liu Q, Qian YH and Xie D: The lncRNA H19 mediates breast cancer cell plasticity during EMT and MET plasticity by differentially sponging $\mathrm{miR}-200 \mathrm{~b} / \mathrm{c}$ and let-7b. Sci Signal 10: 10, 2017.

22. Lv M, Zhong Z, Huang M, Tian Q, Jiang R and Chen J: lncRNA $\mathrm{H} 19$ regulates epithelial-mesenchymal transition and metastasis of bladder cancer by miR-29b-3p as competing endogenous RNA. Biochim Biophys Acta Mol Cell Res 1864: 1887-1899, 2017.

23. Avasarala S, Van Scoyk M, Wang J, Sechler M, Vandervest K, Brzezinski C, Weekes C, Edwards MG, Arcaroli J, Davis RE, et al: hsa-miR29b, a critical downstream target of non-canonical Wnt signaling, plays an anti-proliferative role in non-small cell lung cancer cells via targeting MDM2 expression. Biol Open 2: 675-685, 2013.

24. Weerasinghe P, Garcia GE, Zhu Q, Yuan P, Feng L, Mao L and Jing $\mathrm{N}$ : Inhibition of Stat 3 activation and tumor growth suppression of non-small cell lung cancer by G-quartet oligonucleotides. Int $\mathrm{J}$ Oncol 31: 129-136, 2007.

25. Li JH, Liu S, Zhou H, Qu LH and Yang JH: starBase v2.0: Decoding miRNA-ceRNA, miRNA-ncRNA and protein-RNA interaction networks from large-scale CLIP-Seq data. Nucleic Acids Res 42: D92-D97, 2014.

26. Shin C, Nam JW, Farh KK, Chiang HR, Shkumatava A and Bartel DP: Expanding the microRNA targeting code: Functional sites with centered pairing. Mol Cell 38: 789-802, 2010.

27. Karginov FV, Cheloufi S, Chong MM, Stark A, Smith AD and Hannon GJ: Diverse endonucleolytic cleavage sites in the mammalian transcriptome depend upon microRNAs, Drosha, and additional nucleases. Mol Cell 38: 781-788, 2010.

28. Inamura K: Lung Cancer: Understanding Its Molecular Pathology and the 2015 WHO Classification. Front Oncol 7: 193, 2017. 
29. Livak KJ and Schmittgen TD: Analysis of relative gene expression data using real-time quantitative PCR and the $2(-\Delta \Delta \mathrm{C}(\mathrm{T}))$ method. Methods 25: 402-408, 2001.

30. Chung WJ, Agius P, Westholm JO, Chen M, Okamura K, Robine N, Leslie CS and Lai EC: Computational and experimental identification of mirtrons in Drosophila melanogaster and Caenorhabditis elegans. Genome Res 21: 286-300, 2011.

31. Lee I, Ajay SS, Yook JI, Kim HS, Hong SH, Kim NH, Dhanasekaran SM, Chinnaiyan AM and Athey BD: New class of microRNA targets containing simultaneous 5'-UTR and 3'-UTR interaction sites. Genome Res 19: 1175-1183, 2009.

32. Farh KK, Grimson A, Jan C, Lewis BP, Johnston WK, Lim LP, Burge CB and Bartel DP: The widespread impact of mammalian MicroRNAs on mRNA repression and evolution. Science 310 1817-1821, 2005.

33. Saito M, Shiraishi K, Matsumoto K, Schetter A, Ogata-Kawata H, Tsuchiya N, Kunitoh H, Nokihara H, Watanabe S, Tsuta K, et al: A three-microRNA signature predicts responses to platinum-based doublet chemotherapy in patients with lung adenocarcinoma. Clin Cancer Res 20: 4784-4793, 2014.

34. Yang Y, Li H, Hou S, Hu B, Liu J and Wang J: The noncoding RNA expression profile and the effect of lncRNA AK126698 on cisplatin resistance in non-small-cell lung cancer cell. PLoS One 8: e65309, 2013.

35. Bartolomei MS, Zemel S and Tilghman SM: Parental imprinting of the mouse H19 gene. Nature 351: 153-155, 1991.

36. Tabano S, Colapietro P, Cetin I, Grati FR, Zanutto S, Mandò C, Antonazzo P, Pileri P, Rossella F, Larizza L, et al: Epigenetic modulation of the IGF2/H19 imprinted domain in human embryonic and extra-embryonic compartments and its possible role in fetal growth restriction. Epigenetics 5: 313-324, 2010

37. Byun HM, Wong HL, Birnstein EA, Wolff EM, Liang G and Yang AS: Examination of IGF2 and H19 loss of imprinting in bladder cancer. Cancer Res 67: 10753-10758, 2007.

38. Berteaux N, Lottin S, Monté D, Pinte S, Quatannens B, Coll J, Hondermarck H, Curgy JJ, Dugimont T and Adriaenssens E: H19 mRNA-like noncoding RNA promotes breast cancer cell proliferation through positive control by E2F1. J Biol Chem 280 : 29625-29636, 2005.

39. Cui J, Mo J, Luo M, Yu Q, Zhou S, Li T, Zhang Y and Luo W: c-Myc-activated long non-coding RNA H19 downregulates miR-107 and promotes cell cycle progression of non-small cell lung cancer. Int J Clin Exp Pathol 8: 12400-12409, 2015.

40. Wang Q, Cheng N, Li X, Pan H, Li C, Ren S, Su C, Cai W, Zhao C, Zhang L, et al: Correlation of long non-coding RNA H19 expression with cisplatin-resistance and clinical outcome in lung adenocarcinoma. Oncotarget 8: 2558-2567, 2017.
41. Hu Q, Wang YB, Zeng P, Yan GQ, Xin L and Hu XY: Expression of long non-coding RNA (lncRNA) H19 in immunodeficient mice induced with human colon cancer cells. Eur Rev Med Pharmacol Sci 20: 4880-4884, 2016

42. Kallen AN, Zhou XB, Xu J, Qiao C, Ma J, Yan L, Lu L, Liu C, Yi JS, Zhang H, et al: The imprinted H19 lncRNA antagonizes let-7 microRNAs. Mol Cell 52: 101-112, 2013.

43. Xiong Y, Fang JH, Yun JP, Yang J, Zhang Y, Jia WH and Zhuang SM: Effects of microRNA-29 on apoptosis, tumorigenicity, and prognosis of hepatocellular carcinoma. Hepatology 51: 836-845, 2010

44. Yan B, Guo Q, Nan XX, Wang Z, Yin Z, Yi L, Wei YB, Gao YL, Zhou KQ and Yang JR: Micro-ribonucleic acid 29b inhibits cell proliferation and invasion and enhances cell apoptosis and chemotherapy effects of cisplatin via targeting of DNMT3b and AKT3 in prostate cancer. Onco Targets Ther 8: 557-565, 2015.

45. Wang H, Guan X, Tu Y, Zheng S, Long J, Li S, Qi C, Xie X, Zhang H, Zhang Y, et al: MicroRNA-29b attenuates non-small cell lung cancer metastasis by targeting matrix metalloproteinase 2 and PTEN. J Exp Clin Cancer Res 34: 59, 2015.

46. Zhao X, Liu Y, Li Z, Zheng S, Wang Z, Li W, Bi Z, Li L, Jiang Y, Luo Y, et al: Linc00511 acts as a competing endogenous RNA to regulate VEGFA expression through sponging hsa-miR-29b-3p in pancreatic ductal adenocarcinoma. J Cell Mol Med 22: 655-667, 2018.

47. Ko HJ and Kim YJ: Signal transducer and activator of transcription proteins: Regulators of myeloid-derived suppressor cell-mediated immunosuppression in cancer. Arch Pharm Res 39: 1597-1608, 2016

48. Yu H, Lee H, Herrmann A, Buettner R and Jove R: Revisiting STAT3 signalling in cancer: New and unexpected biological functions. Nat Rev Cancer 14: 736-746, 2014.

49. Calò V, Migliavacca M, Bazan V, Macaluso M, Buscemi M, Gebbia N and Russo A: STAT proteins: From normal control of cellular events to tumorigenesis. J Cell Physiol 197: 157-168, 2003.

50. Siveen KS, Sikka S, Surana R, Dai X, Zhang J, Kumar AP, Tan BK, Sethi G and Bishayee A: Targeting the STAT3 signaling pathway in cancer: Role of synthetic and natural inhibitors. Biochim Biophys Acta 1845: 136-154, 2014.

51. Zhang P, Sun Y and Ma L: ZEB1: At the crossroads of epithelialmesenchymal transition, metastasis and therapy resistance. Cell Cycle 14: 481-487, 2015.

(i) $\Theta$ This work is licensed under a Creative Commons C Attribution-NonCommercial-NoDerivatives 4.0 International (CC BY-NC-ND 4.0) License. 